\title{
OBITUARIO ALEJANDRO ISLA (1944-2019), HASTA SIEMPRE
}

\author{
Héctor González Cortez ${ }^{1}$
}

El 19 de febrero falleció en Buenos Aires el Dr. Alejandro Isla. Su inesperada muerte trajo la oscuridad del invierno al verano de quienes disfrutábamos su entrañable amistad y la humildad del carácter con el que siempre prodigaba generosamente su sabiduría y compromiso. Su partida no solo le duele a su familia y a la antropología argentina, también enluta a la antropología chilena, pues como profesor visitante colaboró en la formación de decenas de graduados de la disciplina en los programas de Magíster y Doctorado que dictan de manera conjunta la Universidad de Tarapacá en Arica y la Universidad Católica del Norte en San Pedro de Atacama.

Alejandro nació el 20 de abril de 1944 en la ciudad de La Plata. Realizó sus estudios de licenciatura en antropología en la Facultad de Ciencias Naturales y Museo de la Universidad Nacional de La Plata, de donde egresó el año 1968. Tempranamente se sintió atraído por el mundo andino, realizando entre 1966 y 1968 sus primeros trabajos de campo en el altiplano boliviano, en la comunidad de Guaraya del cantón Tiwanaku.

Por recomendación de Alberto Rex González, quien había apoyado su formación académica y su estudio en Bolivia, se integró al equipo interdisciplinario encabezado por Esther Hermitte que realizaba una investigación sobre la población aborigen del Gran Chaco, cuyo trabajo de campo se desarrolló entre los años 1969 y 1971. Su experiencia etnográfica con los Tobas pensaba aprovecharla para concluir sus estudios de doctorado en la Universidad Nacional de La Plata, donde había aprobado todos los cursos correspondientes a ese nivel de formación. Pero, desde su época de estudiante, Alejandro combinó su actividad académica con su compromiso social y político, y como consecuencia de su militancia en el movimiento peronista revolucionario, en un país muy convulsionado políticamente, terminó siendo encarcelado en 1975, paradójicamente durante el gobierno de María Estela Martínez de Perón.

Recién logra su libertad en 1983, el año en que la elección de Raúl Alfonsín marca el retorno a la democracia en Argentina. Al salir de la cárcel retomó su actividad académica, y desde fines de 1984 hasta comienzos de 1986 volvió a realizar trabajo de campo en el cantón de Tiwanaku. También reanudó sus estudios en la Universidad de Buenos Aires, donde obtuvo su doctorado en 1996. Su tesis, galardonada con la máxima distinción que entrega esa institución se basó en un investigación que realizó en la comunidad de Amaicha del Valle, en los valles calchaquíes de Tucumán.

Alejandro ingresó como investigador adjunto al CONICET a fines del año 1987. Al momento de su fallecimiento tenía la calidad de investigador principal jubilado. Hasta inicios de los años 1990, sus temas de investigación se concentraron en problemáticas vinculadas a las poblaciones rurales e indígenas del Noroeste Argentino, de la puna boliviana y argentina, de los valles calchaquíes tucumanos y de la provincia de Chaco; abordando también sectores populares de San Miguel de Tucumán y San Salvador de Jujuy. Desde 1993, en el marco de su participación en proyectos internacionales, especialmente el dirigido por Julie Taylor (Argentine Democracy and the Lure of Authoritarianism, 1993-1994), sus intereses se volcaron hacia el estudio la violencia urbana y política en conglomerados urbanos, primero en la provincia de Tucumán y luego a nivel nacional.

En 1997 se hace cargo del Área (en ese entonces Programa) en Antropología Social y Política de FLACSO Argentina, que dirigió hasta el momento de su fallecimiento. Fue colaborador de diferentes programas de postgrado en su país. Como mencionamos al inicio de esta nota, fue profesor visitante en el Magíster y Doctorado dictado en alianza por las Universidades de Tarapacá y Católica del Norte desde el año 2002. En el seminario a su cargo, trataba de vincular los aspectos más abstractos de la teoría y la metodología, con su utilización como herramientas en el campo de la investigación empírica. Para ello, aparte de entregar el vínculo genealógico de las teorías más actuales de la antropología con las escuelas clásicas, incorporaba

\footnotetext{
${ }^{1}$ Departamento de Antropología, Universidad de Tarapacá, Arica, Chile. hgonzalezcl@yahoo.es

http://dx.doi.org/10.4067/S0717-73562019005000601. Publicado en línea 3-abril-2019.
} 
casos de estudio para su discusión, intentando que sus alumnos aprovecharan su experiencia de investigación en el desarrollo de sus propios intereses de estudio.

Alejandro fue un destacado académico, tanto como profesor como investigador, que contó con el reconocimiento de sus pares y alumnos. Pero, por sobre ello, fue una persona generosa, con un gran compromiso social. Despedimos a un colega y amigo entrañable. Acompañamos a su familia, esposa e hijos en el dolor de su pérdida. 